\title{
Maintaining remission of ulcerative colitis with the probiotic Escherichia coli Nissle 1917 is as effective as with standard mesalazine
}

\author{
W Kruis, P Frič, J Pokrotnieks, M Lukáš, B Fixa, M Kaščák, M A Kamm, J Weismueller, C Beglinger, \\ M Stolte, C Wolff, J Schulze
}

See end of article for authors' affiliations

.....................

Correspondence to: Dr W Kruis, Evangelisches Krankenhaus Kalk Buchforststr 2, 51103 Cologne, Germany; ansorg@evkk.de

Revised version received 1 April 2004

Accepted for publication 13 April 2004
Background and aim: Evidence exists for the pathogenic role of the enteric flora in inflammatory bowel disease. Probiotics contain living microorganisms which exert health effects on the host. We compared the efficacy in maintaining remission of the probiotic preparation Escherichia coli Nissle 1917 and established therapy with mesalazine in patients with ulcerative colitis.

Patients and methods: In total, 327 patients were recruited and assigned to a double blind, double dummy trial to receive either the probiotic drug $200 \mathrm{mg}$ once daily $(\mathrm{n}=162)$ or mesalazine $500 \mathrm{mg}$ three times daily $(n=165)$. The study lasted for 12 months and patients were assessed by clinical and endoscopic activity indices (Rachmilewitz) as well as by histology. The primary aim of the study was to confirm equivalent efficacy of the two drugs in the prevention of relapses.

Results: The per protocol analysis revealed relapses in 40/110 (36.4\%) patients in the $E$ coli Nissle 1917 group and $38 / 112(33.9 \%$ ) in the mesalazine group (significant equivalence $p=0.003$ ). Subgroup analyses showed no differences between the treatment groups in terms of duration and localisation of disease or pretrial treatment. Safety profile and tolerability were very good for both groups and were not different.

Conclusions: The probiotic drug E coli Nissle 1917 shows efficacy and safety in maintaining remission equivalent to the gold standard mesalazine in patients with ulcerative colitis. The effectiveness of probiotic treatment further underlines the pathogenetic significance of the enteric flora.
U lcerative colitis (UC) is a chronic relapsing disease. The aims of treatment are induction of remission and prevention of relapses. Guidelines ${ }^{12}$ recommend aminosalicylates for maintenance treatment. Aminosalicylates exert various effects on leukotrienes, cytokines, and oxygen radicals. ${ }^{3}$ Their mode of action in UC remains unclear. It is suggested that the sum of their anti-inflammatory activities constitutes their therapeutic principle. Thus maintenance treatment with aminosalicylates is only effective when inflammation starts, but not in the non-inflamed gut.

Growing evidence exists for a role of the intestinal microflora in the pathogenesis of inflammatory bowel disease (IBD). Findings from genetically engineered animal models as well as clinical observations have elucidated the importance of commensal bacteria..$^{4-6}$ Antibacterial treatment showed some beneficial effects ${ }^{7}$ but the use of antibiotics is limited. Therefore, treatment with probiotics has been proposed.

Probiotics are viable non-pathogenic microorganisms that confer health benefits to the host by improving the microbial balance of the indigenous microflora. ${ }^{9}$ Apart from anecdotal experience, two controlled studies with the probiotic bacterial strain Escherichia coli Nissle 1917 (EcN) in UC already exist. $^{1011}$ These trials showed no difference between the relapse preventing effects of EcN and standard mesalazine. However, some criticism was raised as to the validity of these studies. ${ }^{12}{ }^{13}$ The present study was undertaken to confirm that the relapse preventing effects of probiotic therapy with EcN and standard mesalazine are equivalent.

\section{MATERIALS AND METHODS}

The study was conducted according to the Helsinki Declaration (revised version of Hong Kong) and adhered to good clinical practice (GCP) guidelines. The study was approved by the Ethikkommission der Ärztekammer Nordrhein, Germany, as well as by the local ethics committees of the participating centres. All patients received material in their own language and gave written informed consent. Patients were included in the study if aged 1870 years and diagnosed with UC in remission (clinical activity index $(\mathrm{CAI}) \leqslant 4$, endoscopic index $(\mathrm{EI}) \leqslant 4$, and no signs of acute inflammation on histological examination). In addition, inclusion criteria comprised at least two acute attacks of UC prior to the study and a duration of the current remission of no longer than 12 months. Exclusion criteria were: active UC; proctitis with up to $10 \mathrm{~cm}$ proximal spread; Crohn's disease; infectious colitis; severe accompanying illnesses or major colonic surgery; use of antibiotics, sulphonamides, steroids, or other therapies for UC at entry into the trial; administration of EcN within the previous six months before trial entry; as well as known intolerance to salicylates.

\section{Study medication}

The investigational drug was a bacterial preparation for oral use containing non-pathogenic Escherichia coli of strain Nissle 1917 (serotype O6:K5:H1). Capsules were enteric coated to protect the microorganisms from gastric juice and contained $2.5-25 \times 10^{9}$ viable bacteria (Mutaflor $100 \mathrm{mg}$; Ardeypharm $\mathrm{GmbH}$, Herdecke, Germany). The control preparation was mesalazine, consisting of eudragit L coated 5-aminosalicylic

Abbreviations: UC, ulcerative colitis; IBD, inflammatory bowel disease; EcN, Escherichia coli Nissle 1917; GCP, good clinical practice; CAl, clinical activity index; $\mathrm{El}$, endoscopic index; ITT, intention to treat population; PP, per protocol population; 5-ASA, 5-aminosalicylic acid 
acid (Salofalk500 mg; Dr Falk Pharma GmbH, Freiburg, Germany). The test group received one capsule of Mutaflor $100 \mathrm{mg}$ once daily and one tablet of placebo three times daily from day 1 to day 4, and two capsules of Mutaflor $100 \mathrm{mg}$ once daily and one tablet of placebo three times daily from day 5 to the end of the study. The control group received one capsule of placebo once daily and one tablet of Salofalk $500 \mathrm{mg}$ three times daily from day $\mathrm{l}$ to day 4, and two capsules of placebo once daily and one tablet of Salofalk $500 \mathrm{mg}$ three times daily from day 5 to the end of the study.

No concomitant medication for UC was allowed throughout the study.

\section{Study design}

This was a randomised, double blind, double dummy trial comparing the relapse preventing effects and safety of a bacterial preparation containing viable $\mathrm{EcN}$ and mesalazine for 12 months in patients with UC in remission. The study was conducted in 60 hospitals and private settings in 10 European countries (see list of participating investigators in the appendix).

Randomisation was carried out in a double blind manner in blocks of four patients using 1:1 allocation to the two treatment groups. Only complete blocks of random numbers were used for each centre. If patients were eligible for study entry, they were assigned to random numbers (= patient numbers) in ascending order within each centre according to the chronological order of their randomisation and were given the corresponding study medication.

\section{Evaluation}

Clinic visits were required at the start and end of the study as well as after $1,2,3,6$, and 9 months of treatment.

The primary objective of the study was to compare the number of patients experiencing a relapse of UC during the 12 month observation period between the two treatment groups. Patients were classified as suffering a relapse when all three of the following criteria were met: CAI $>6$ or an increase in CAI of at least 3 points with CAI $=4$ being exceeded at the same time; EI $>4$; and histological signs of acute inflammation. CAI was defined according to Rachmilewitz. ${ }^{14}$

At trial entry and at the end of the study, patients underwent colonoscopy where biopsies were taken. Endoscopic activity was assessed using a four point index ${ }^{14}$ : granularity, vascular pattern, vulnerability of mucosa, and mucosal damage. All biopsies were examined by a single pathologist using a four point scale. ${ }^{15}$

Secondary efficacy variables were the physician's and patient's assessment of general well being and calculation of a quality of life index. ${ }^{16}$ Additionally, time to relapse, CAI, EI, and histological findings were documented.

Laboratory assessments, including erythrocyte sedimentation rate, C reactive protein, orosomucoids, blood counts, liver enzymes, creatinine, serum iron, and serum albumin were performed at trial entry and at the end of the study. Incidence and severity of adverse events were reported according to GCP for clinical trials of medication in the European Community (91/507/EWG, CPMP/ICH/135/95). Tolerance of the study medication was assessed on a four point scale (very good, good, fair, poor), and patient compliance was ascertained by pill counting.

\section{Statistical analysis}

The aim of the study was to statistically confirm one sided equivalent efficacy of $\mathrm{ECN}$ and mesalazine in preventing relapses of UC. Relapse rates were compared using the one sided test of Farrington and Manning ${ }^{17}$ : this tests the null hypothesis that the difference between treatment groups is greater than or equal to the upper equivalence margin $\Delta$ of $20 \%$ versus the alternative that the true difference is less than $20 \%(\alpha=0.05$; upper confidence limit $95 \%)$. Assuming a 12 month relapse rate of $30 \%$ under mesalazine treatment and $35 \%$ under EcN treatment, to reach a statistical power of $80 \%$ at least $\mathrm{n}=127$ patients were required in each treatment group according to the sample size term for comparative binomial trials with the null hypothesis of non-zero risk difference. ${ }^{17}$ Two sets of patients were analysed: an intention to treat population (ITT), including all patients who took at least one dose of the study medication, and a per protocol

Table 1 Demographic data and prestudy clinical characteristics

\begin{tabular}{|c|c|c|c|c|}
\hline \multirow[b]{2}{*}{ Characteristic } & \multicolumn{2}{|l|}{ IT population } & \multicolumn{2}{|c|}{ PP population } \\
\hline & $\begin{array}{l}\text { EcN } \\
(n=162)\end{array}$ & $\begin{array}{l}\text { Mesalazine } \\
(n=165)\end{array}$ & $\begin{array}{l}\text { EcN } \\
(n=110)\end{array}$ & $\begin{array}{l}\text { Mesalazine } \\
(n=112)\end{array}$ \\
\hline \multicolumn{5}{|l|}{ Demographic data } \\
\hline Males & $56.8 \%$ & $52.7 \%$ & $55.5 \%$ & $50.9 \%$ \\
\hline Age (y) (median (range)) & $43(19-69)$ & $41(19-82)$ & $41(19-69)$ & $42(19-74)$ \\
\hline \multicolumn{5}{|l|}{ Localisation of UC } \\
\hline Sub-/total & $26(16.1 \%)$ & $35(21.3 \%)$ & $16(14.6 \%)$ & $24(21.5 \%)$ \\
\hline Left sided & 27 (16.7\%) & $35(21.2 \%)$ & $16(14.5 \%)$ & $26(23.2 \%)$ \\
\hline Distal & $102(63.0 \%)$ & $88(53.4 \%)$ & $74(61.8 \%)$ & $57(44.6 \%)$ \\
\hline \multicolumn{5}{|l|}{ Duration of UC } \\
\hline$\leqslant 5 y$ & $71(43.8 \%)$ & $84(50.9 \%)$ & $48(43.6 \%)$ & $52(46.4 \%)$ \\
\hline$>5 y$ & $91(56.2 \%)$ & $81(49.1 \%)$ & $62(56.4 \%)$ & $60(53.6 \%)$ \\
\hline \multicolumn{5}{|c|}{ Treatment before study (single/combined therapy) } \\
\hline \multicolumn{5}{|c|}{ Oral salicylates $(\mathrm{mg})^{*}$} \\
\hline$\leqslant 1500$ & $60(37.4 \%)$ & $68(41.2 \%)$ & $41(37.3 \%)$ & $46(41.1 \%)$ \\
\hline$\leqslant 3000$ & $46(28.4 \%)$ & $47(28.5 \%)$ & $30(27.3 \%)$ & 35 (31.3\%) \\
\hline$>3000$ & $7(4.3 \%)$ & $7(4.2 \%)$ & $7(4.6 \%)$ & $4(3.6 \%)$ \\
\hline Clinical activity index & $0.9(1.2)$ & $0.9(1.2)$ & $0.8(1.0)$ & $0.6(1.0)$ \\
\hline Endoscopic index & $1.9(1.6)$ & $1.8(1.5)$ & $1.5(1.2)$ & $1.5(1.3)$ \\
\hline \multicolumn{5}{|l|}{ Histology (rectum) } \\
\hline No signs of active disease & $77.8 \%$ & $79.4 \%$ & $94.5 \%$ & $93.8 \%$ \\
\hline Quality of life score & $24(4.1)$ & $25.2(3.7)$ & $24.5(3.9)$ & $24.4(4.0)$ \\
\hline Smoker & $10(6.2 \%)$ & $11(6.7 \%)$ & $8(7.3 \%)$ & $9(8.0 \%)$ \\
\hline
\end{tabular}




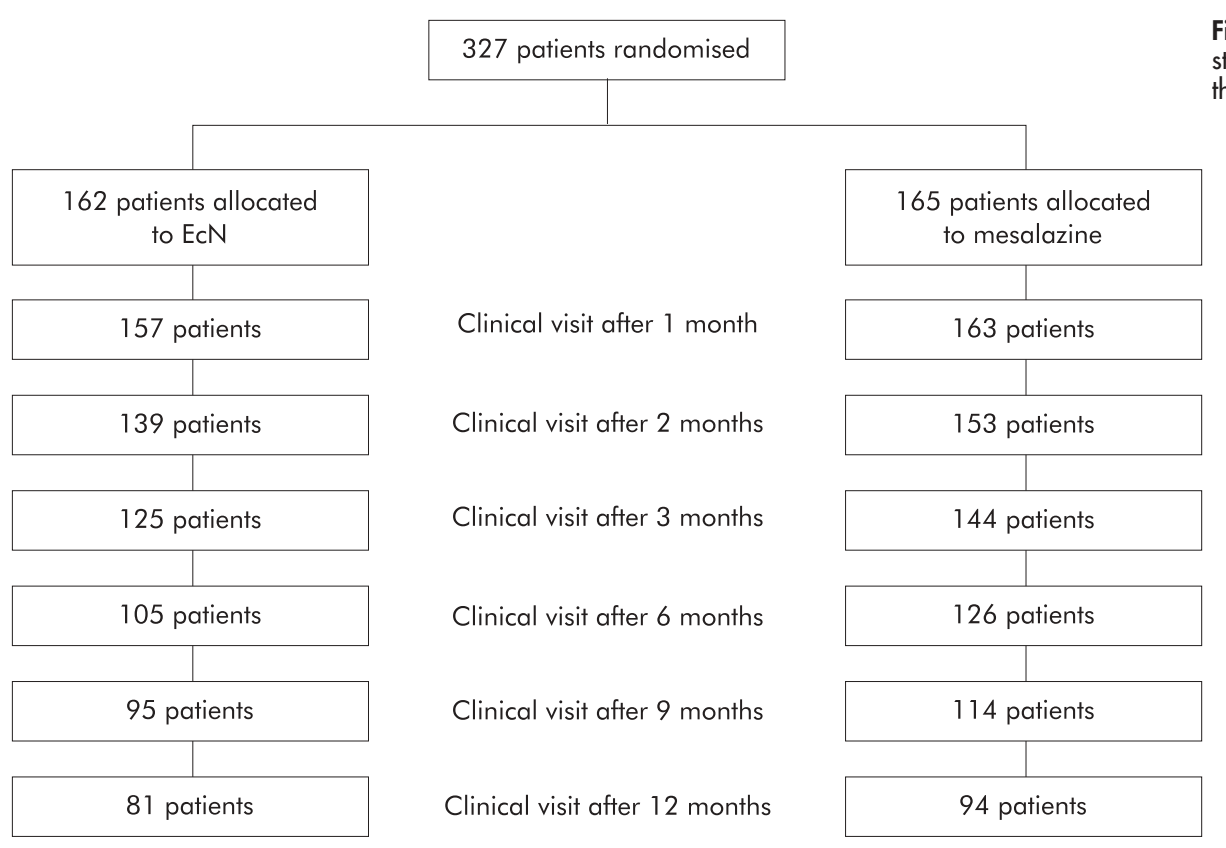

population (PP). According to generally accepted standards for equivalence and non-inferiority trials, ${ }^{18}$ primary analysis of the main objective (difference in relapse rates) was based on the PP population. Assuming $25 \%$ protocol violators, a total number of 160 patients in each treatment group was therefore planned.

Baseline comparability and statistical analysis of secondary objectives was assessed using Fisher's exact test (two sided; $\alpha=0.05)$. In addition, Kaplan-Meier curves were plotted. If no CAI or other parameter was documented at the individual study end, the "last observation carried forward" method was applied. Results are given as mean (SD). Statistical tests were executed using SPSS software package version 10.0 under the Microsoft Windows NT operating system. For exploratory comparisons (tables 2,3), the Student's $t$ test was used.

\section{RESULTS}

\section{Patient characteristics}

In total, 327 patients were enrolled and randomised to either the EcN preparation $(n=162)$ or mesalazine $(n=165)$. The two patient groups were matched with regard to demographic, clinical, and pretreatment characteristics (table 1). The time gap between the end of the last relapse before the study and entry into the study was not longer than four weeks in $11.1 \%$ of patients receiving $\mathrm{EcN}$ and in $9.1 \%$ receiving mesalazine, and not longer than three months in
Figure 1 Number of patients in the study at the time of clinical visits and at the final examination.

Table 2 Reasons for premature discontinuation of the study

\begin{tabular}{lcc}
\hline Reason for premature discontinuation* & EcN (n= 162) & Mesalazine (n= 165) \\
\hline Deterioration of disease (relapse not included) & $1(0.6 \%)$ & $1(0.6 \%)$ \\
Newly emerged exclusion criterion during study & $4(2.5 \%)$ & $2(1.2 \%)$ \\
Patient's request & $13(8.0 \%)$ & $9(5.5 \%)$ \\
Adverse events & $3(1.9 \%)$ & $6(3.6 \%)$ \\
Insufficient patient compliance & $6(3.7 \%)$ & $6(3.6 \%)$ \\
Insufficient patient cooperation (diary) & $6(3.7 \%)$ & $3(1.8 \%)$ \\
Patient did not appear anymore & $2(1.2 \%)$ & $5(3.0 \%)$ \\
Other reasons & $1(0.6 \%)$ & $2(1.2 \%)$ \\
Patients with premature discontinuation & $19(11.7 \%)$ & $20(12.1 \%)$ \\
\hline *Multiple reasons possible. & & \\
EcN, Escherichia coli Nissle 1917. & &
\end{tabular}




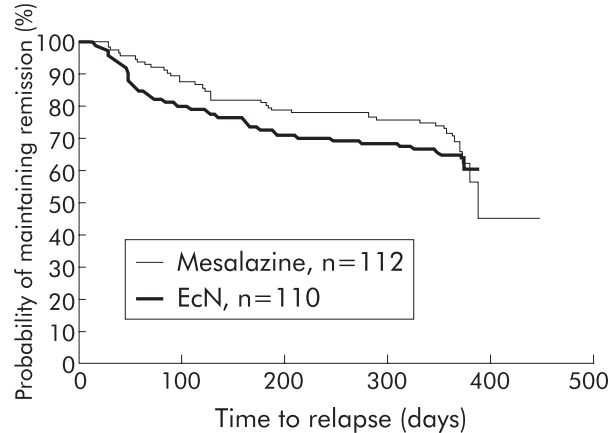

Figure 3 Probability of remaining in remission in the Escherichia coli Nissle 1917 (EcN) and mesalazine groups.

point (EcN 29 patients, mesalazine 24 patients). Accordingly, the PP analysis set comprised 222 patients (EcN 110, mesalazine 112). Mean duration of the study observation period was 250 (144) (median 357) days in the EcN group and 287 (125) (median 360) days in the mesalazine group. The number of patients in the study at the scheduled visits is shown in fig 1. Premature discontinuation of the study for reasons other than relapse of disease occurred in 39/327 $(11.9 \%)$ patients (in $19 / 162(11.7 \%)$ patients in the EcN group and in 20/165 (12.1\%) patients in the mesalazine group) (table 2). Newly emerged exclusion criteria during the study were start of concomitant medication in four patients on EcN. One patient on mesalazine became afraid of 5-aminosalicylic acid (5-ASA) and another patient underwent cardiac surgery.

\section{Relapse (primary objective)}

PP analysis revealed relapse in 40/110 (36.4\%) patients in the EcN group and in 38/112 (33.9\%) patients in the mesalazine group (fig 2), resulting in significant equivalence between the two groups $(p=0.003)$. The corresponding one sided upper 95\% confidence limit for the difference in treatment was $12.8 \%$ (that is, within the equivalence range of $20 \%$ ).

Figure 3 depicts the probability of remaining in remission by Kaplan-Meier curves. Median time to relapse in the EcN group could not be calculated due to the large number of late censorings. In the mesalazine group it was 386 days.

ITT analysis confirmed these results, showing a relapse rate of $45.1 \%$ in the $\mathrm{EcN}$ group and $37.0 \%$ in the mesalazine group (significant equivalence $p=0.013$ ). The upper limit of the $95 \%$ confidence interval for the difference in treatment was $16.9 \%$.

\section{Subgroup analyses (secondary objectives)}

All subgroup analyses were performed in the ITT population. CAI increased in all patients by 1.8 (3.4) points over the study period, showing a slightly larger increase in the $\mathrm{ECN}$ group $(2.4(3.7))$ than in the mesalazine group $(1.2(3.0))$. No differences were observed in EI or histology between the start and end of the study (fig 4). Table 3 lists relapse rates with regard to duration, localisation, and pretrial treatment. There were no significant differences between the treatment groups for any of these characteristics. Quality of life scores on admission were 24.5 (3.9) in the EcN group and 24.4 (4.0) in the mesalazine group. Respective values after 12 months were 24.3 (5.2) and 25.1 (3.9). No significant changes occurred during the 12 month observation period.

\section{Safety and tolerance}

As rated by the patients, overall tolerance was very good or good in the EcN group in $80.0 \%$ and in the mesalazine group in $86.0 \%$. According to the physician's assessment, the respective values were $85.1 \%$ and $90.3 \%$.

Discontinuation of the study medication due to adverse events (relapse included) occurred in $22(6.7 \%)$ patients (11 $(6.8 \%)$ in the EcN group and $11(6.9 \%)$ in the mesalazine group). Most frequent reasons were gastrointestinal disorders such as bloody stools, nausea, diarrhoea, mucous secretion (EcN $4.3 \%$, mesalazine $4.2 \%$ ), and abdominal pain (EcN $0.6 \%$, mesalazine $2.4 \%$ ).

Generally, no unexpected drug reactions occurred during the study. No deaths but 17 serious adverse events were reported in 13/327 (4\%) patients (EcN 7, mesalazine 6). Each serious adverse event occurred only once.

Adverse events were reported in 68/162 (42.0\%) patients treated with EcN and in 58/165 (35.2\%) patients treated with mesalazine. Many adverse events reflect symptoms common for active UC such as bloody stools (4.6\%), diarrhoea (5.8\%),

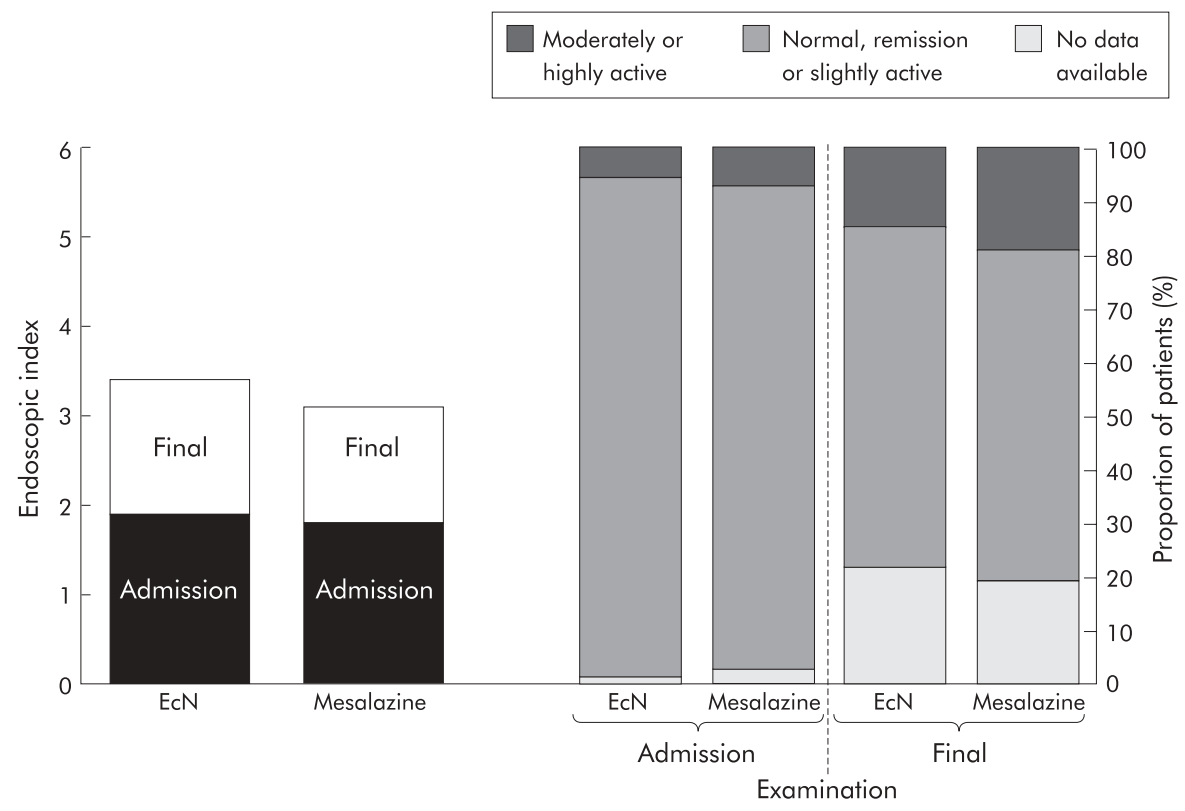

Figure 4 Endoscopic index and histology at the start and end of the study in the Escherichia coli Nissle 1917 (EcN) and mesalazine groups. 


\begin{tabular}{|c|c|c|c|c|}
\hline \multirow[b]{2}{*}{ Characteristic } & \multicolumn{2}{|l|}{$\mathrm{EcN}$} & \multicolumn{2}{|c|}{ Mesalazine } \\
\hline & $\%$ & $n$ & $\%$ & $\mathbf{n}$ \\
\hline \multicolumn{5}{|l|}{ Duration of UC } \\
\hline$<5 y$ & 46.5 & $33 / 71$ & 32.1 & $27 / 84$ \\
\hline$>5 y$ & 44.0 & $40 / 91$ & 42.0 & $34 / 81$ \\
\hline \multicolumn{5}{|l|}{ Localisation of UC } \\
\hline Sub-/total & 46.2 & $12 / 26$ & 34.3 & $12 / 35$ \\
\hline Left sided & 63.0 & $17 / 27$ & 31.4 & $11 / 35$ \\
\hline Distal & 41.2 & $42 / 102$ & 40.9 & $36 / 88$ \\
\hline \multicolumn{5}{|l|}{ Pretreatment } \\
\hline Oral salicylates* & 45.1 & $51 / 113$ & 37.7 & $46 / 122$ \\
\hline
\end{tabular}

and abdominal pain (8.5\%). The most frequent nonintestinal adverse events were viral infections (EcN 4.9\%, mesalazine $4.2 \%)$, nausea $(3.1 \%, 3.0 \%)$ and headache $(1.9 \%$, $0.6 \%)$. Laboratory tests showed no significant alterations.

\section{DISCUSSION}

Most controlled trials are designed to test differences in efficacy. In contrast, our trial was aimed at proving equivalence. Indeed, we demonstrated that the probiotic EcN provides significantly equivalent efficacy in preventing relapses of UC and is not inferior to the established gold standard mesalazine. This result was not only confirmed by statistical analysis of the PP population, which is preferred in equivalence studies, ${ }^{18}$ but also by ITT analysis.

Therapeutic efficacy is usually demonstrated by superiority in a placebo controlled trial. In serious disease however when effective therapy exists that has already been tested by comparison with placebo, additional placebo controlled trials may be considered unethical. ${ }^{18}$ A meta-analysis ${ }^{19}$ reviewed 16 studies of maintenance therapy involving 2341 patients with UC. In four of these 16 trials, preparations containing 5-ASA were compared with placebo; in the remaining 12 studies sulphasalazine was compared. 5-ASA was observed to be significantly more effective than placebo in all dosage subgroups ( $<1 \mathrm{~g} /$ day, l-1.9 g/day, $\geqslant 2 \mathrm{~g} /$ day). A dose dependent trend was not observed. ${ }^{19}$ Indeed, some studies comparing at least two doses were performed showing mainly negative or conflicting results ${ }^{20}$ : Pentasa $3 \mathrm{~g} /$ day was not superior to $1.5 \mathrm{~g} /$ day; balsalazide $4 \mathrm{~g}$ /day was better than $2 \mathrm{~g} /$ day; balsalazide $6 \mathrm{~g} /$ day was better than $3 \mathrm{~g} /$ day in one study but in another trial was similarly effective; and two studies with olsalazine reached different conclusions. Thus superior efficacy of doses higher than $1.5 \mathrm{~g} /$ day has not been established..$^{20}$ It can be stated that mesalazine $1.5 \mathrm{~g} /$ day presently reflects the standard in the prevention of UC relapses and thus it qualifies as a control in an equivalence trial.

Previous studies on EcN were criticised ${ }^{12} 13$ for several reasons-for example, short observation period ${ }^{10}$ or heterogeneity of patients and outcome parameters. ${ }^{11}$ The present trial considered this critique and followed actual standards. The observation period was 12 months, only patients with UC in remission were included, and the clinical outcome was assessed by well established endoscopic and histological activity indices resulting in a low relapse rate for the mesalazine group comparable with previous publications. ${ }^{19}$ A total of 327 patients were included to achieve a statistical power sufficient to test for equivalence in a one sided set.

Most likely, IBD is caused by an unrestrained inflammatory response to as yet undefined agents. Although precise identification of the antigenic stimuli has not been determined, the intestinal microflora represents a likely culprit. $^{42122}$ To manipulate the resident gut bacteria therefore seems to offer a rational approach to maintaining remission in IBD. One way of doing this, which has gained credence over recent years, is by using probiotics. ${ }^{23}$

Mechanisms which may account for probiotic activity include production of antimicrobial agents, inhibition of adhesion of pathogens, and influence on mucosal barrier function. ${ }^{13}$ It was reported that inhibition of nuclear factor $\kappa \mathrm{B}$ could be mediated by probiotic microorganisms. ${ }^{24}$ The properties of EcN are well characterised ${ }^{25}$ and its genome has been extensively analysed. ${ }^{26}$ It carries non-pathogenic adhesion molecules. A specific lipopolysaccharide renders it immunogenic without showing any immunotoxic properties. $^{27}$ Immunomodulating activity was demonstrated for specific immune responses as well as for induction of nonspecific natural immunity in preterm infants. ${ }^{28} \mathrm{EcN}$ develops antagonistic activity against enterobacteria such as Salmonella enteritidis, Shigella dysenteriae, Yersinia enterocolitica, and Vibrio cholerae. $^{29}{ }^{30}$ It prevents invasion of Salmonella typhimurium into intestinal cells, ${ }^{31}$ inhibits adhesion and invasion of adherent invasive $E$ coli, ${ }^{32}$ and reduces concentrations of mucosa associated colonic microflora constituents in UC. ${ }^{33}$

$\mathrm{EcN}$ is safe. Molecular genetics as well as functional analyses have revealed that EcN does not produce any virulence factors or carry any genes for pathogenicity traits. ${ }^{34}$ It does not bear genes for antibiotic resistance, transferable genes or plasmids, and does not take up foreign pathogenic DNA. No formation of enterotoxins, cytotoxins, or haemolysins has been observed and there is no serum resistance. ${ }^{25} 2629$ Clinical studies have demonstrated a favourable safety profile for EcN compared with placebo, ${ }^{35} 36$ mesalazine, ${ }^{10}{ }^{11}$ and lactulose. ${ }^{37}$ Our study confirms this excellent safety and tolerance record.

There are other controlled studies with different probiotics. Relapse prevention with Lactobacillus GG tested negatively for maintenance therapy in surgically induced remission of Crohn's disease ${ }^{38}$ but a small study showed positive results when Saccharomyces boulardii was added to mesalazine. ${ }^{39}$ Inflammation of the ileal pouch constructed after proctocolectomy and ileoanal anastomosis in patients with UC is of particular interest because bacterial growth seems to be of pivotal pathophysiological significance. Cases successfully treated with EcN have been reported. ${ }^{40} \mathrm{~A}$ formulation comprising eight different probiotic bacteria demonstrated convincing therapeutic effects in primary prevention ${ }^{41}$ and chronic pouchitis..$^{42}$ In an uncontrolled study, this preparation was able to colonise the gut and maintain remission in patients with UC. ${ }^{43}$ 
In conclusion, the use of probiotics in IBD is in accordance with its pathogenesis. They may prevent induction of inflammatory reactions. EcN shows therapeutic efficacy and safety in maintaining remission in UC. It can be considered as an alternative to mesalazine.

\section{Authors' affiliations \\ W Kruis, Evangelisches Krankenhaus Kalk, University of Cologne, Germany \\ P Frič, Ustředná vojenská nemocnice, II interní oddělení, Praha, Czech Republic \\ J Pokrotnieks, Paula Stradina Clinical University Hospital, Riga, Latvia M Lukáš, IV Interni Klinika, Charles University, Praha, Czech Republic B Fixa, 2nd Department of Medicine, Charles University Prague, Medical Faculty, Hradec Kralove, Czech Republic \\ M Kašcák, Interné oddelenie NsP, Trenčín, Slovak Republic \\ M A Kamm, St Mark's Hospital, London, UK \\ J Weismueller, Private Practice, Koblenz, Germany \\ C Beglinger, Division of Gastroenterology, University Hospital, Basel, Switzerland \\ M Stolte, Institut für Pathologie, Klinikum Bayreuth, Germany \\ C Wolff, J Schulze, Ardeypharm, Herdecke, Germany}

\section{APPENDIX}

The following institutions, local principal investigators, and local coordinators participated in this study:

Austria: University Hospital, Graz: W Petritsch.

Czech Republic: Nemocnice Milosrdnych sester sv Karla Boromejského, Prague: J Dosedel; University Hospital, Hradec Kralove: B Fixa; Central Military Hospital, Prague: P Frič; University Hospitals, Prague: M Kment, M Lukáš; University Hospital Plzen: J Koželuhová; University Hospital Brno: H Simonová; Masaryk Hospital, Ústí nad Labem: K Mareš, J Stehlík.

Estonia: Central Hospital, Tallin: B Margus; University Hospital, Tartu: R Salupere.

Germany: Private Practice, Essen: A Boekstegers; University Hospital, Jena: H Bosseckert; University Hospital, Regensburg: V Gross; DRK-Kliniken Westend, Berlin: R Büchsel; Charité-Campus Virchow, Berlin: A Dignass; Private Practice, Rottenburg aN: F Dreher; Private Practice, Frankenberg: R Engelhard; Private Practice, Bad Homburg: G Ermert; Private Practice, Karlsruhe: U Farack; Private Practice, Marburg: J Hein; Kreisklinik München-Pasing, München: J Heinkelein; Mittelrhein-Klinik Bad Salzig, Boppard: R Herz; Private Practice, Bautzen: I König; Ev Krankenhaus Kalk, Köln: W Kruis; Private Practice, Münster: Th Krummenerl; Private Practice, Cottbus: A Kühn; Israelitisches Krankenhaus, Hamburg: P Layer; University Hospital, Dresden: G Lobeck; Charité-Humboldt-University, Berlin: $\mathrm{H}$ Lochs; Private Practice, Neuenkirchen: $\mathrm{R}$ Moellmann; Private Practice, Cottbus: E Muehlberg; University Hospital Großhadern, München: Th Ochsenkühn; Städtisches Klinikum Friedrichstadt, Dresden: H Porst; Krankenhaus Tabea, Hamburg: A Raedler; University Hospital, Erlangen: M Raithel; Krankenhaus Nordwest, Frankfurt: W Rösch; University Hospital, Bonn: Ch Scheurlen; Private Practice, Gera: U Schindler; Private Practice, Reutlingen: W Schmeißer; Private Practice, Regensburg: E Schütz; Krankenhaus Speyerer, Heidelberg: R Singer; University Hospital Benjamin Franklin, Berlin: R Stange; University Hospital, Frankfurt: J Stein; Klinikum der RWTH, Aachen: Th Schönfelder; University Hospital, Mainz: R Wanitschke; Private Practice, Koblenz: A Lütke, J Weismüller; St Michael Krankenhaus, Völklingen: D Woerdehoff; Private Practice, Erlangen: J Zeus.

Latvia: Paula Stradina Clinical University Hospital, Riga: J Pokrotnieks.

Lithuania: University Hospital, Vilnius: A Irnius; Kauno Medicinos Akademija, Kaunas: L Kupcinskas.
Slovak Republic: Comenius University Hospital, Bratislava: M Huorka; City Hospital, Trencíne: M Kaščák; University Hospital, Košice: T Hildebrand.

Sweden: Sabbatsberg Naersjukhuset, Stockholm: P Benno; Karolinska Institutet: A Uribe.

Switzerland: Kantonsspital-University, Basel: Ch Beglinger.

UK: Leeds General Infirmary, Leeds: ATR Axon; St Mark's Hospital, London: MA Kamm.

\section{REFERENCES}

1 British Society of Gastroenterology. Clinical practice guidelines: inflammatory bowel disease, 1996. www.bsg.org.uk/clinical-prac/guidelines.htm.

2 Stange EF, Riemann J, von Herbay A, et al. Diagnosis and therapy of ulcerative colitis - results of an evidence-based consensus conference of the German Society of Digestive and Metabolic Diseases. Z Gastroenterol 2001;39:19-20.

3 Travis SP, Jewell DP. Salicylates for ulcerative colitis - their mode of action. Pharmacol Ther 1994;63:135-61

4 Shanahan F. Probiotics and inflammatory bowel disease: is there a scientific rationale? Inflamm Bowel Dis 2000;6:107-15.

5 D'Haens GR, Geboes K, Peeters M, et al. Early lesions of recurrent Crohn's disease caused by infusion of intestinal contents in excluded ileum. Gastroenterology 1998;1 14:262-7.

6 Sartor RB. Postoperative recurrence of Crohn's disease: the enemy is within the fecal stream. Gastroenterology 1998;114:398-400.

7 Rutgeerts P, Hiele M, Geboes K, et al. Controlled trial of metronidazole treatment for prevention of Crohn's recurrence after ileal resection. Gastroenterology 1995; 108:1617-21.

8 Hulten K, Almashhrawi A, El Zaatari FA, et al. Antibacterial therapy for Crohn's disease: a review emphasizing therapy directed against mycobacteria. Dig Dis Sci 2000;45:445-56.

9 Hart AL, Stagg AJ, Kamm MA. Related articles, links use of probiotics in the treatment of inflammatory bowel disease. J Clin Gastroenterol 2003:36:111-19.

10 Kruis W, Schütz E, Fric $P$, et al. Double-blind comparison of an oral Escherichia coli preparation and mesalazine in maintaining remission of ulcerative colitis. Aliment Pharmacol Ther 1997;11:853-8.

11 Rembacken BJ, Snelling AM, Hawkey PM, et al. Non-pathogenic Escherichia coli versus mesalazine for the treatment of ulcerative colitis: a randomised trial. Lancet 1999;354:635-9.

12 Folwaczny C. Probiotics for prevention of ulcerative colitis recurrence: alternative medicine added to standard treatment? Z Gastroenterol 2000:38:547-50.

13 Faubion WA, Sandborn WJ. Probiotic therapy with E. coli for ulcerative colitis: take the good with the bad, Gastroenterology 2000;1 18:630-1.

14 Rachmilewitz D. Coated mesalazine (5-aminosalicylic acid) versus sulphasalazine in the treatment of active ulcerative colitis: a randomised trial. BMJ 1989:298:82-6.

15 Riley SA, Mani V, Goodman MJ, et al. Microscopic activity in ulcerative colitis: what does it mean? Gut 1991;32:174-8.

16 Guyatt G, Mitchell A, Irvine EJ, et al. A new measure of health status for clinical trials in inflammatory bowel disease. Gastroenterology 1989;96:804-10.

17 Farrington CP, Manning G. Test statistics and sample size formulae for comparative binomial trials with null hypothesis of non-zero risk difference of non-unity relative risk. Stat Med 1990;9:1447-54.

18 Note for guidance on statistical principles for clinical trials. International conference on harmonisation. CPMP/ICH 363/96, 1998. http:// www.emea.eu.int/pdfs/human/ich/036396en.pdf

19 Sutherland LR, Roth DE, Beck PL. Alternatives to sulfasalazine: A metaanalysis of 5-ASA in the treatment of ulcerative colitis. Inflamm Bowel Dis 1997;3:65-78.

20 Riley SA. What dose of 5-aminosalicylic acid (mesalazine) in ulcerative colitis? Gut 1998;42:761-3.

21 Sartor RB. Enteric microflora in IBD: pathogens or commensals? Inflamm Bowel Dis 1997;3:230-5.

22 Campieri M, Gionchetti P. Bacteria as the cause of ulcerative colitis. Gut 2001;48:132-5.

23 Hamilton-Miller JMT. A review of clinical trials of probiotics in the management of inflammatory bowel disease. Infect Dis Rev 2001;3:83-7.

24 Neish AS, Gewirtz AT, Zeng H, et al. Prokaryotic regulation of epithelial responses by inhibition of IkappaB-alpha ubiquitination. Science 2000;289:1560-3.

25 Blum G, Marre R, Hacker J. Properties of Escherichia coli strains of serotype O6. Infection 1995;23:234-6.

26 Blum-Oehler G. The scanned bacterium: Analysis of the microbial genome. 4th Interdisciplinary Symposium: Internal microflora in symbiosis and pathogenicity. Berlin 2000. Hagen: Alfred-Nissle-Gesellschaft eV, 2001:23-31.

27 Grozdanov L, Zaehringer U, Blum-Oehler G, et al. A single-nucleotide exchange in the wzy gene is responsible for the semi-rough O6 LPS phenotype and serum sensitivity of Escherichia coli strain Nissle 1917. J Bacteriol 2002; 184:5912-25

28 Cukrowska B, Lodinova-Zadnikova R, Enders C, et al. Specific proliferative and antibody responses of premature infants to intestinal colonization with nonpathogenic probiotic E. coli strain Nissle 1917. Scand J Immunol 2002;55:204-9. 
29 Schulze J, Sonnenborn U. Oral administration of a certain strain of live Escherichia coli for intestinal disorders? Infection 1995;23:184-6.

30 Schulze J, Lorenz A, Mandel L. Colonisation of Escherichia coli in different gnotobiotic animal models. Microb Ecol Health Dis 1992;5:iv-v.

31 Oelschläger TA, Altenhoefer A, Hacker J. Inhibition of Salmonella typhimurium invasion into intestinal cells by the probiotic E. coli strain Nissle 1917. Gastroenterology 2001;120(suppl):A326.

32 Boudeau J, Rich C, France CF, et al. Escherichia coli strain Nissle 1917 inhibits adhesion to and invasion of intestinal epithelial cells by adherentinvasive E. coli isolated from a Crohn's disease patient. Gastroenterology 2001;120(suppl):A190

33 Swidsinski A, Swidsinski S, Godzun A, et al. Therapy with E. coli Nissle reduces concentrations of mucosa associated colonic flora in patients with ulcerative colitis. Gastroenterology 2000;118(suppl):A1138.

34 Schulze J, Sonnenborn U. The role of the gut flora in inflammatory bowel diseases. In: Shimoyama T, Axon A, Lee A, et al, eds. In: Helicobacter meets inflammatory bowel disease. Tokyo: Medical Tribune Inc, 2002:393-417.

35 Möllenbrink M, Bruckschen E. Treatment of chronic constipation with physiologic Escherichia coli bacteria. Results of a clinical study of the effectiveness and tolerance of microbiological therapy with the E. coli Nissle 1917 strain (Mutaflor). Med Klin 1994;89:587-93.
36 Malchow HA. Crohn's disease and Escherichia coli. A new approach in therapy to maintain remission of colonic Crohn's disease? J Clin Gastroenterol 1997; 25:653-8

37 Bruckschen E, Horosiewicz H. Chronic constipation. Comparision of microbiological therapy and lactulose. MMW 1994;136:241-5.

38 Prantera C, Scribano ML, Falasco G, et al. Ineffectiveness of probiotics in preventing recurrence after curative resection for Crohn's disease: a randomised controlled trial with Lactobacillus GG. Gut 2002;51:405-9

39 Guslandi M, Mezzi G, Sorghi M, et al. Saccharomyces boulardii in maintenance treatment of Crohn's disease. Dig Dis Sci 2000;45:1462-4.

40 Kuzela L, Kašcák M, Vavrecka A. Induction and maintenance of remission with nonpathogenic Escherichia coli in patients with pouchitis. Am J Gastroenterol 2001;96:3218-19.

41 Gionchetti P, Rizzello F, Helwig U, et al. Prophylaxis of pouchitis onset with probiotic therapy: a double-blind, placebo-controlled trial. Gastroenterology 2003; 124:1202-9.

42 Gionchetti P, Rizzello F, Venturi A, et al. Oral bacteriotherapy as maintenance treatment in patients with chronic pouchitis: a double-blind, placebocontrolled trial. Gastroenterology 2000;1 19:305-9.

43 Venturi A, Gionchetti P, Rizzello F, et al. Impact on the composition of the faecal flora by a new probiotic preparation: preliminary data on maintenance treatment of patients with ulcerative colitis. Aliment Pharmacol Ther $1999 ; 13: 1103-8$

\section{Clinical Evidence-Call for contributors}

Clinical Evidence is a regularly updated evidence based journal available worldwide both as a paper version and on the internet. Clinical Evidence needs to recruit a number of new contributors. Contributors are health care professionals or epidemiologists with experience in evidence based medicine and the ability to write in a concise and structured way.

\section{Currently, we are interested in finding contributors with an interest in} the following clinical areas:

Altitude sickness; Autism; Basal cell carcinoma; Breast feeding; Carbon monoxide poisoning; Cervical cancer; Cystic fibrosis; Ectopic pregnancy; Grief/bereavement; Halitosis; Hodgkins disease; Infectious mononucleosis (glandular fever); Kidney stones; Malignant melanoma (metastatic); Mesothelioma; Myeloma; Ovarian cyst; Pancreatitis (acute); Pancreatitis (chronic); Polymyalgia rheumatica; Post-partum haemorrhage; Pulmonary embolism; Recurrent miscarriage; Repetitive strain injury; Scoliosis; Seasonal affective disorder; Squint; Systemic lupus erythematosus; Testicular cancer; Varicocele; Viral meningitis; Vitiligo However, we are always looking for others, so do not let this list discourage you.

\section{Being a contributor involves:}

- Appraising the results of literature searches (performed by our Information Specialists) to identify high quality evidence for inclusion in the journal.

- Writing to a highly structured template (about 2000-3000 words), using evidence from selected studies, within 6-8 weeks of receiving the literature search results.

- Working with Clinical Evidence Editors to ensure that the text meets rigorous epidemiological and style standards.

- Updating the text every eight months to incorporate new evidence.

- Expanding the topic to include new questions once every 12-18 months.

If you would like to become a contributor for Clinical Evidence or require more information about what this involves please send your contact details and a copy of your CV, clearly stating the clinical area you are interested in, to Claire Folkes (cfolkes@bmigroup.com).

\section{Call for peer reviewers}

Clinical Evidence also needs to recruit a number of new peer reviewers specifically with an interest in the clinical areas stated above, and also others related to general practice. Peer reviewers are health care professionals or epidemiologists with experience in evidence based medicine. As a peer reviewer you would be asked for your views on the clinical relevance, validity, and accessibility of specific topics within the journal, and their usefulness to the intended audience (international generalists and health care professionals, possibly with limited statistical knowledge). Topics are usually 2000-3000 words in length and we would ask you to review between 2-5 topics per year. The peer review process takes place throughout the year, and our turnaround time for each review is ideally 10-14 days.

If you are interested in becoming a peer reviewer for Clinical Evidence, please complete the peer review questionnaire at www.clinicalevidence.com or contact Claire Folkes(cfolkes@bmigroup.com). 